\title{
Selected Architectural Terms
}

$\mathrm{N}^{\circ}$ ote: These are just a few terms that occur in this volume. Some are new, others perhaps just not in general use in the Tikal series.

\section{Aggregate}

In concrete small stones or gravel are essential as stuff that the cement can stick to. Without aggregate concrete is mere grout with little strength as a mass.

\section{Basal Platform}

A substructure body exclusively sustaining a lower substructure platform.

\section{Batter}

Non-vertical faces are battered. Leaning outward is negative batter, inward is positive.

\section{Beam}

A spanning member is a beam. Wood beams are common but stone ones are known, particularly as lintels.

\section{Building}

The part of a structure that stands on a building platform and contains accessible rooms.

\section{Building Platform}

A building platform anticipates the plan of the building and provides a basis for the walls (see also "Fake Building Platform," below).

\section{Butt}

The parts of beams that bear on their supports are their butts. Some butts are concealed, others exposed.

\section{Construction Stage}

Major works of architecture at Tikal display a standard set of the following features: basal platform, pyramid, lower substructure platform, supplementary platform, building platform, building, and roofcomb. Building and building platform appear most frequently, and others appear on various structures in various combinations. They are numbered from topmost to basal, but described in reverse order, that is, basal to topmost. Although the terms imply distinct stages of construction, this is not always the case. For example, some building platforms are not stages of construction at all, and many buildings present walls, vaults, and upper zones as distinct constructional modules that perhaps might best be designated as substages, though this has not been formalized.

\section{Capstone}

Stones bridging the gap between half-vaults are capstones. Wood members bridging half-vault gaps are known and may be described as wooden capstones.

\section{Cord Holder}

Recessed pegs to which cords could be tied, usually found in interior wall faces flanking doorway openings, often in sets of four.

\section{Epicentral Tikal}

This term refers to the parts of the city center that are interconnected by continuous plaster paving. The nine structures described in this volume are all within it. Individual location maps for each structure depict part of epicentral Tikal. By means of the causeway system, the epicenter extends from the Great Plaza to the North Group and to Great Temple VI. Since plaster paving is inherently frag- 
ile, maintaining such an extensive paving must have been important and meaningful.

\section{Fake Building Platform}

Beginning in Middle Classic times at Tikal, and evident only in certain structures, the building platform is no more than a series of moldings at the foot of exterior building wall faces. In some cases, this is obvious; in others, the building platform image is entirely convincing and requires excavation to show its true nature. It may be that many Late Classic Tikal structures display apparent building platforms that appear to support walls, but in fact are no more than exterior facade treatments.

\section{Falsework}

A timber structure set up during construction to establish lines, angles, and heights. Evidence consists only of socket holes.

\section{Half-vault}

From Intermediate through the Late Classic at Tikal vaults were installed by halves, first on one side of a room and then for completion, on the other side. The two half-vaults do not touch or lean against each other; each is independently stable. Short end-vault units prevent the long half-vaults from rolling into the room space.

\section{Header}

A facing stone set with its length projecting into the hearting of the wall or other feature.

\section{Jamb}

The sides of doorway openings are called jambs.

\section{Lintel}

A beam over a doorway, window, or niche is a lintel beam. Most lintels at Tikal employ a number of beams, many seemingly much too small in diameter for the load imposed by the vault mass and they must have been braced until vault mortar had reached full set.

\section{Lower Substructure Platform}

A number of structures consist of a building, a building platform, and a lower substructure platform that does not conform to definitions for supplementary platforms, pyramids, or basal platforms. These are designated simply as lower substructure platforms.

\section{Medial Molding}

At wall-top level a corbel course projecting out over the exterior wall surface is known as a medial molding.

\section{Outset}

Terraces, walls, and roofcombs, often have elements of surface projected out from other elements. Some may have iconographic significance, particularly rear axial outsets and stair-side outsets. Even side outsets might have carried meanings that would have been known to the people using the structures.

\section{Preplastered}

Workers sometimes applied plaster to masonry units prior to setting them in place. This is seen only on capstones in Late Classic construction and hence they provide a reliable diagnostic to this era at Tikal.

\section{Range}

Rooms of a building arranged with their length perpendicular to the structure axis constitute a "range." This is the basis of the term "range-type structure." Some range-type structures have more than one range set one in front of the other.

\section{Rear Axial Outset}

Certain structures have axial outsets in their rear facades, designated as rear axial outsets. These do not appear to serve any structural function and are not accessible as ledges on which persons might stand. They seem to have some significance in themselves, and they correlate with a definite set of other architectural features that may define temples.

\section{Return Face}

This term applies to facets of exterior surface that run perpendicular to the general orientation of facades_-for example, end elements of outsets.

\section{Riser}

The vertical interval from tread to tread on a stair is a riser.

\section{Rod Row}

A series of small holes usually found immediately below a medial molding or a vault spring is known as a 
rod row. These holes are castes left by dowels only a few centimeters in diameter.

\section{Roofcomb}

A superstructure body, not supplied with accessible rooms, erected on a roof.

\section{Rope Anchor}

This is a fitting similar to a cord holder but much larger.

\section{Socket}

The hole left by a rotted out beam is a socket.

\section{Soffit}

The under-surface of a projecting member is its soffit. Vault surfaces over a room are soffit surfaces.

\section{Spall}

Small stones that occur in masonry joints and beds are spalls. Some may have been placed so as to provide a correct setting for the blocks, others may have been included in the mortar.

\section{Stair-side Outset}

Terrace outsets flanking stairs are known as stair-side outsets.

\section{Stair-Side Ramp}

Some outset stairs present sheer edges, while others have a slightly raised ramp-like edge, also known by the terms "alfarda" and balustrade.

\section{Standing Architecture}

Tikal ruins include many architectural structures only partially collapsed. Project operations cleared debris away from many of these, but others were left as originally found. These are known as examples of standing architecture and were recorded without removal of collapsed material or vegetation.

\section{Stretcher}

A facing stone set with its length running in the plane of the surface.

\section{Subapron}

Apron profiles at Tikal are of two main types: two-element aprons and three-element aprons. The two-element type typifies Early Classic work and consists of an upper part projecting over a lower part; the lower part is the subapron. This implies that the upper part is the apron, although the term "apron" is also applied to the whole feature whether two element or three element. In three-element aprons the subapron is the middle part.

\section{Subspring Beam}

Beams spanning rooms and set below vault spring height are subspring beams.

\section{Substructure}

The parts below the building are known collectively as the substructure.

\section{Supplementary Platform}

A substructure body intervening between a lower substructure platform and a building platform.

\section{Tread}

The horizontal part of a stair between risers is a tread.

\section{Upper Zone}

The exterior element corresponding to the vaults and overhanging exterior wall faces is the upper zone.

\section{Vault}

Masonry constructions that span over rooms or chambers are vaults. The vaults at Tikal are unlike arches in that one side does not depend on the other, they do not exert lateral thrusts, and do not require buttresses.

\section{Vault-back}

Some vaults have outer surfaces underlying upper zone material; these are known as vault-back surfaces. Some vaults at Tikal do not have vault-backs but most do.

\section{Vault Beam}

All known vaults at Tikal contain either wood beams, beam butts, or beam sockets. The beams are known as vault beams and in many cases were installed prior to masonry work as part of falsework and/or formwork. The way that vault soffit stones were cut around beams shows that the beams were in place first.

\section{Veneer Facings}

Facing stones proportioned so that their height is 
distinctly greater than their thickness are known as veneer stones.

\section{Wall}

Elements installed to define rooms are designated as walls. Surfaces of platforms are not referred to as walls, but as faces.

\section{Wall Top}

In Late Classic work at Tikal, masons completed wall construction by plastering inside and out and across the top of the walls. Wall-top plaster is a reliable diagnostic of Late Classic construction at Tikal. 